\title{
Reduce the Influence of Horizontal and Vertical Cold Joints on the Behavior of High Strength Concrete Beam Casting in Hot Weather by Using Sugar Molasses
}

\author{
Fatimah Hameed Naser Al-Mamoori*1, Ali Hameed Naser Al-Mamoori² \\ ${ }^{1}$ Hydraulic Structures Department, College of Water Resources Engineering, University of AL-Qasim Green Hilla, Iraq \\ ${ }^{2}$ Civil Engineering Department, College of Engineering, University of Karbala Hilla, Iraq \\ *Corresponding Author E-mail:fatimah_mamoori@yahoo.com
}

\begin{abstract}
The current research studies the effect of cold joints on the behavior shear and flexure of High Strength Concrete (HSC) beams caused by delayed casting sequence during the hot weather in summer of Iraq.

Fresh concrete should be kept alive during the various casting batches for concrete element by re-vibration. However, the over vibration caused loss in homogeneity and it is difficult to keep the workability of concrete during hot weather due to the effect of setting time.

To deal with this problem of improper casting sequence, which eventually leads to the formation of cold joints, it will be used sugar waste (named as Sugar Molasses (SM)) is a by-product resulted from refining process of sugar as a delayed agent to increase the setting time in order to prevent early set of concrete due to adverse effects in construction joint of hot weather.

In the current study, the first objective aims to investigate some of fresh and hardened mechanical properties of HSC (with high cement content) using SM at percentages of $(0,0.05,0.1,0.2,0.3) \%$ from the weight of cement under the concept of sustainable development. The second objective aims to investigate the location and surface texture effect of horizontal and vertical cold joints on the flexural and shear behavior of beam with/without SM. This objective includes testing of twenty four plain concrete beam of $(110 \times 110 \times 650 \mathrm{~mm})$ under two point load; half of them casting without roughing (smooth) the old layer and the other casted after roughed it.

SM content of $0.2 \%$ of cement weight can improve compressive strength by about $11.2 \%$ at 28 days and delay initial setting time by about 4.617 hours (277 minutes). No adverse effect on concrete have been observed at this dosage of SM concentration for the ages of concrete cylinders studied. Delays in the setting of concrete at this dosage of SM content help in reducing the early setting of concrete and therefore reduced the impact of the cold joints formation in concrete beams under Iraqi hot weather condition. The failure load for the beams with SM of smooth and rough vertical joints is in the range between $(1.95-2.12)$ and $(1.46-1.37)$; respectively times that of the case of beam without SM.
\end{abstract}

Keywords: beam, cold/construction joint, flexure, HSC, mechanical properties, PH-Value, setting time, shear, slump test, Sugar Molasses (SM), unusually casting sequence.

\section{Introduction}

The process of pouring the entire structure once and monolithically is difficult especially when the size of the concrete elements are large; it is accompanied by several restrictions on the availability of the fresh concrete supply that is depends on the mixer size, staff size, and the available time. Therefore, it is poured the concrete into the structural elements in two or more batches.

The delay in the concrete placement process due to many causes in addition to the inappropriate casting sequence can lead to cold joints formation commonly called (construction joint).

There are many guidelines available on the performance and location of joints in the case of normal concrete in order to avoid the discontinuity or weakness plane formed but, the requirements for high strength concrete (HSC) in hot weather have not been found when the casting is delayed for limited hours, when the first part of the cast is nearly reached to initial setting; especially in the hot summer days in Iraq and when the concrete mixture is HSC with high content of cement.
In order to avoid cold joints, the concrete pouring should be resumed significantly before the concrete reach to initial setting time. For unusually long delays during concrete placement, the concrete must survive by periodically revibrating it. However, the concrete should not be vibrated continuously to causing the segregation. Moreover, if the concrete reached to the time of initial setting, vibration should be stopped and concrete should be allowed to harden. Therefore, a cold joint will be formed, and the suitable surface must be prepared to it.

Depended on the plane of joint construction, there are four types; vertical, horizontal, transverse and longitudinal joints. Horizontal and vertical joints types used in beam, while the horizontal joints used in massive concrete structures and in columns. The transverse and longitudinal joints are most suitable to use in each of bridge decks, slabs, tunnels and pavements. [1] The effects of temperature on the concrete strength has been presented by many researchers. These researches show that high temperature effects on the magnitude evaporation from the surface of fresh concrete and the evaporation has a pronounced effect on fresh concrete, as more water is needed to keep a certain slump. [2] 
Retarding agents means the admixture that delay the cement hydration i.e. increases the time of setting. Many chemical admixtures alter the cement paste hydration through generally incomprehensible mechanisms. Sugar has long been known to retard set and hydration. A phenomenon discovered by chance when it was observed that cement stored in old sugar bags failed to properly setting. [3] Other problems were historically encountered when the water was contaminated with the presence of sugar traces as in the concrete floor placed in the candy factory. [4] There are many types of starches and sugars retard the hydration of cement and set, including some water-reducing agents containing lignosulfonates. While other types of sugars are retarders, some are more effective than others. [5]

Sugar Molasses (SM) is a by-product of viscous refining processes of sugar cane in sugar factories. The molasses composition is variable and depends on the specificity of raw materials and conditions of manufacturing.

Disposal of waste materials has a negative impact on the environment. Thus, there was a sophisticated pattern of waste use for multiple purposes. Therefore, SM were used as an alternative to replacement of admixture in concrete because it plays a role as sugar.

The effect of sugar on some fresh and hardened properties of mortar and concrete have been studied by many authors; Ashworth [6], Thomas and. Birchall [7], Luke and Luke [8], Juenger and Jennings [9], Abalaka [10] \&[11], and Mazumder [12]. However, these studies have been often focused on conventional mortar and less of them on normal strength concrete in normal weather condition. There is no study yet on the effect of using SM that resulted from the Iraqi sugar factories in HSC (with high cement content) in hot summer in Iraq. Therefore, in current research we will resolve the behavior of fresh and hardened HSC properties by adding (mixing) SM as admixtures and using it to casting beam in order to study the effect of it on the delay concreting process on horizontal and vertical construction joints.

Extensive experimental and many theoretical studies have been performed to investigate the effect of construction joint on the behavior of structural element as examples; Husain and Hamza [13], Metwally and Issa [14], Abdul-Majeed [15], Abdul-Majeed et al. [16], Abass [17] and Ali and. Mahdi [18]; but those researchers focused on the cases when the first part of the casting concrete reaches to the final setting time (after one days or more). The main purpose of conducting this paper is to study the effect of SM on construction joint in hot weather in cases get it later batches of pouring concrete; after several hours when the initial time setting is very close.

\section{Objectives and Experimental Program}

The first objective of current research includes several goals that related to investigating the effect of using sugar waste (SM) results from Iraqi factories on HSC and cement paste at percentages of adding $(0,0.05,0.1,0.2,0.3) \%$ from the weight of cement as retarder agent in Iraqi hot summer under the sustainable environment attention as follows:

- the effect of SM on workability of HSC (with high content of cement) (slump test at 0, 30, 60, 90 and 120 ) min.

- the effect of SM on the cylinder compressive strength of HSC at three ages which are 7,14 and 28 days for all mixes.

- the effect of SM on the standard consistency, initial and final setting times on the cement paste for all percentages.

- investigation the PH value of concrete for all mixes.

The second objective aims to investigate the location effect of horizontal and vertical construction joints related to improper casting sequence of fresh concrete (after 120 minutes) on the flexural and shear behavior of beam with/without SM $(0.2 \%$ weight of cement/according to the results getting from the first objective) in the hot weather condition. This objective includes testing of twenty four plain concrete beam of $(110 \times 110 \times 650 \mathrm{~mm})$ under two point load; half of them casting without roughing (smooth) surface of the old layer and the other casted after roughed it. The type and location of construction joints shown in "Tab. 1".

The flexure and shear reinforcement of concrete beam was eliminated in order to understanding pure behavior of beam under the effect of different locations and types of cold joint with/without SM in hot weather conditions.

Table 1: Details of cold joints beam specimens

\begin{tabular}{|c|c|c|}
\hline Series No. & Beam symbol & \multirow{2}{*}{$\begin{array}{c}\text { Type and Location of Joint } \\
\text { Without Construction Joint }\end{array}$} \\
\hline \multirow{6}{*}{ 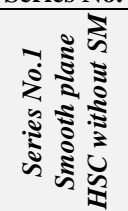 } & B1 & \\
\hline & B2 & Horizontal cold joint, $25 \%$ depth filled \\
\hline & B3 & Horizontal cold joint, $50 \%$ depth filled \\
\hline & B4 & Horizontal cold joint, $75 \%$ depth filled \\
\hline & B5 & Vertical cold joint, $33 \%$ length filled \\
\hline & B6 & Vertical cold joint, $50 \%$ length filled \\
\hline \multirow{6}{*}{ 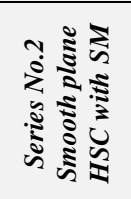 } & B7 & Without Construction Joint \\
\hline & B8 & Horizontal cold joint, $25 \%$ depth filled \\
\hline & B9 & Horizontal cold joint, $50 \%$ depth filled \\
\hline & B10 & Horizontal cold joint, $75 \%$ depth filled \\
\hline & B11 & Vertical cold joint, $33 \%$ length filled \\
\hline & B12 & Vertical cold joint, $50 \%$ length filled \\
\hline \multirow{6}{*}{ 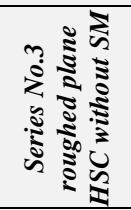 } & $\mathrm{B} 13=\mathrm{B} 1$ & Without Construction Joint \\
\hline & B14 & Horizontal cold joint, $25 \%$ depth filled \\
\hline & B15 & Horizontal cold joint, $50 \%$ depth filled \\
\hline & B16 & Horizontal cold joint, $75 \%$ depth filled \\
\hline & B17 & Vertical cold joint, $33 \%$ length filled \\
\hline & B18 & Vertical cold joint, $50 \%$ length filled \\
\hline \multirow{6}{*}{ 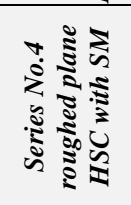 } & $\mathrm{B} 19=\mathrm{B} 7$ & Without Construction Joint \\
\hline & $\mathrm{B} 20$ & Horizontal cold joint, $25 \%$ depth filled \\
\hline & $\mathrm{B} 21$ & Horizontal cold joint, $50 \%$ depth filled \\
\hline & B22 & Horizontal cold joint, $75 \%$ depth filled \\
\hline & $\mathrm{B} 23$ & Vertical cold joint, $33 \%$ length filled \\
\hline & B24 & Vertical cold joint, $50 \%$ length filled \\
\hline
\end{tabular}




\section{Material Properties and Mix Proportion}

The cement used is ordinary Portland cement Known as (Kar). The chemical analysis for this cement is meeting with the limits of the Iraqi Specification IQS No.5-1984 [19] and the physical properties listed in "Tab. 2". Al-Akaidur natural sand within the zone 2 were used in this research; this sand satisfied the requirements of the limits of the Iraqi Specification No.45/1984 [20]. Crushed coarse aggregate from Al-Nebai quarry of maximum aggregate size 14 $\mathrm{mm}$ were used. The limits of physical and chemical properties compliance to the IQS No. 45-1984 [20].

In this work use Sugar Molasses (SM); the byproduct liquid material of Sugar Factory in Babylon City of Iraq as a concrete retarder admixture. The chemical composition of it are listed in "Tab. 3" and "Fig. 1" show this liquid material. Working water was used for all concrete processes.

Table 2: Physical Properties of Cement

\begin{tabular}{|c|c|c|c|}
\hline \multicolumn{2}{|c|}{ Physical Properties } & Test Results & Limits of IQS No.5:1984 \\
\hline \multirow{2}{*}{ Compressive Strength, (MPa) } & 3days & 26.35 & $\geq_{15}$ \\
\hline & 7days & 33.47 & $\geq_{23}$ \\
\hline \multicolumn{2}{|c|}{ Fineness( Blaine) (m2/kg) } & 348 & $\geq_{230}$ \\
\hline \multicolumn{2}{|c|}{ Setting Time (Initial) ( min.) } & 138 & $\geq_{45}$ \\
\hline \multicolumn{2}{|c|}{ Setting Time(Final) ( min.) } & 237 & $\leq_{600}$ \\
\hline
\end{tabular}

Table 3: Chemical Analysis of Sugar Molasses

\begin{tabular}{|c|c|} 
Table 3: Chemical Analysis of Sugar Molasses \\
\hline Test & Result \\
\hline Brix & 83 \\
\hline ph & 5.37 \\
\hline Ash & 9.4 \\
\hline R.S & 12.1 \\
\hline TR.S & 71.2 \\
\hline Sucros & 59.1 \\
\hline
\end{tabular}

After many trial mixes were done according to ACI 363R-92 [21]; and depending on the previous researchers of HSC mix of Mehta and Monteiro (2006) [22] with several changes to satisfy the limit of cylinder compressive strength for HSC.

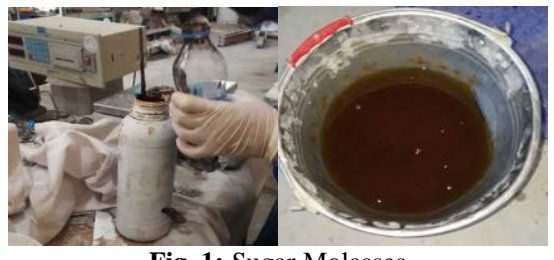

Fig. 1: Sugar Molasses

To study the effect SM admixture, all mixes have the same mix proportions. The mix by weight was $1: 1.731: 1.689$ for cement, sand and coarse aggregates; respectively. The water cement ratio was equal to 0.376 and cement content was $516 \mathrm{~kg} / \mathrm{m}^{3}$. The SM was used at $(0,0.05,0.1,0.2,0.3) \%$ weight of cement; which added to the concrete mixture by mixing with water.

\section{Mixing, Casting and Curing of Concrete Specimens}

Mixing, casting and curing of concrete cylinder specimens of $(150 \times 300 \mathrm{~mm})$ and beams were performed depended on ASTM C192, 2005 [23] as shown in "Fig. 2".

The cylinder specimens for the prepared fresh concrete is casting totally for all mold; for all mixes at different percentages of SM and for each beam. The beam is poured by the fresh concrete partially for the specified volumes. The remaining filling of the beam is casting with the new freshly mix after $120 \mathrm{~min}$. The waterproof thin paces of plywood is used for the creating the joint surface. The two main types of the cold joints are vertical and horizontal. The roughed surface is producing on the casted face by using strong steel rod by scrabing. All cylinder specimens were tested after 7, 14 and 28 days and beams at 28 days of water curing.

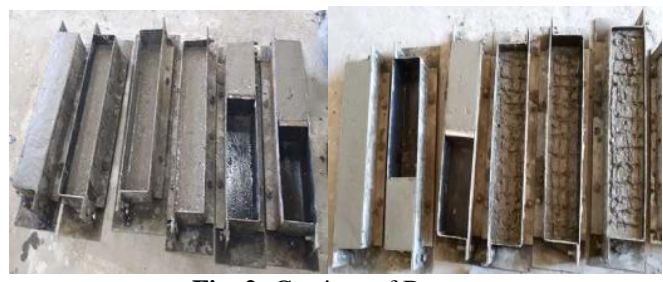

Fig. 2: Casting of Beams

\section{Cement Paste and Concrete Tests}

In fresh state of concrete, the slump test of HSC is performed in accordance with ASTM C143-05 [24]. In hardened state of concrete, the cylinder compressive strength of concrete $(150 \times 300$ $\mathrm{mm}$ ) was tested according to ASTM C39-05 [25] for each mix with different percentages of SM added. For each casting beam; splitting tensile strength $(100 \times 200 \mathrm{~mm})$ according to ASTM C496-04 [26] was performed in addition to cylinder compressive strength.

All beams were tested in a universal testing machine with capacity of $150 \mathrm{kN}$ under monotonic two point load up to ultimate load as shown in "Fig. 3". The cracks were detected and drawn on the side face of the tested beams in addition to measure the location and load of failure

In order to monitor the chemical processes of SM in in cementitious materials, the $\mathrm{pH}$ value test were performed in the solutions of concrete by using $\mathrm{pH}$ indicator strips according to standard ASTM F710 [27] and the use of a pH-meter on concrete sample powder after 28 days in dilution.

The standard consistency and Initial and final setting time of a cement paste were performed at all percentages of SM according to the IQS No.5 -1985 [19].

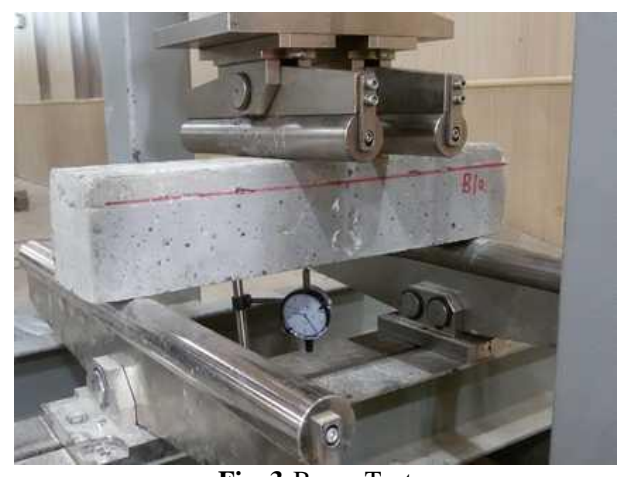

Fig. 3:Beam Test 


\section{The Effect of Sugar Molasses on Setting Time}

The normal consistency of water content was found to be 0.31 for cement paste. "Tab. 4" presents the experimental results of setting time.

Table 4: Molasses Concentration, Initial and Final Setting Time

\begin{tabular}{|c|c|c|}
\hline \multirow{2}{*}{$\begin{array}{c}\text { Sugar added as \% } \\
\text { weight of cement }\end{array}$} & \multicolumn{2}{|c|}{ Setting Time (Minutes : Hours) } \\
\cline { 2 - 3 } & Initial & Final \\
\hline 0 & $138: 2.300$ & $237: 3.950$ \\
\hline 0.05 & $147: 2.450$ & $301: 5.017$ \\
\hline 0.1 & $205: 3.417$ & $423: 7.050$ \\
\hline 0.2 & $415: 6.917$ & $675: 11.250$ \\
\hline 0.3 & $663: 11.050$ & $2300: 38.330$ \\
\hline
\end{tabular}

The SM is very active as a retarder admixture; the increases in initial and final setting times are obviously apparent from a SM content of $0.05 \%$, this concentration are delaying final setting time up to 5 hours while control mix has only 4 hours.

The optimum SM concentration for which good amount of retardation was $0.1 \%$ for medium projects and between $0.1 \%-0.2 \%$ for big projects under hot weather conditions. For higher concentration of SM (more than $0.2 \%$ ), acts as very retarder comparing with the control mix (without molasses); it was reached to more than one and half days at concentration of $0.3 \%$ and prevented the molds being opened and handled for two days after casting.

Setting times are getting longer with increase of the concentration percentage. "Fig. 4" shown the relationship between setting time and molasses percentages for initial and final. From this figure, it can be noted that the effect of increase of molasses percentage showed obviously in final setting more than in initial setting.

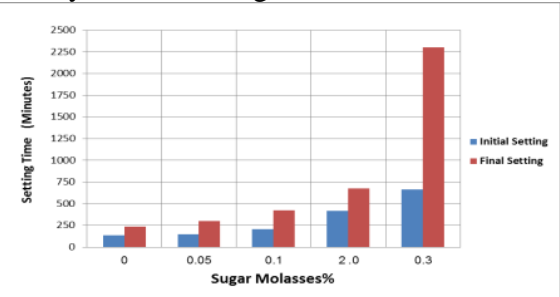

Fig. 4: Relationship Between Setting Time and Sugar Molasses\%

According to the previous results that mentioned in above, the SM used from Sugar Factory in Babylon can be categorized as a retarder admixture. From the relationship below in "Fig. 5", it can be calculated the extra time needed for the concrete operations such as transporting, placing, vibrating and finishing or other cases that required delays in setting concrete according to the corresponding SM concentration which added to mixture of concrete in order to getting the desired initial setting time.

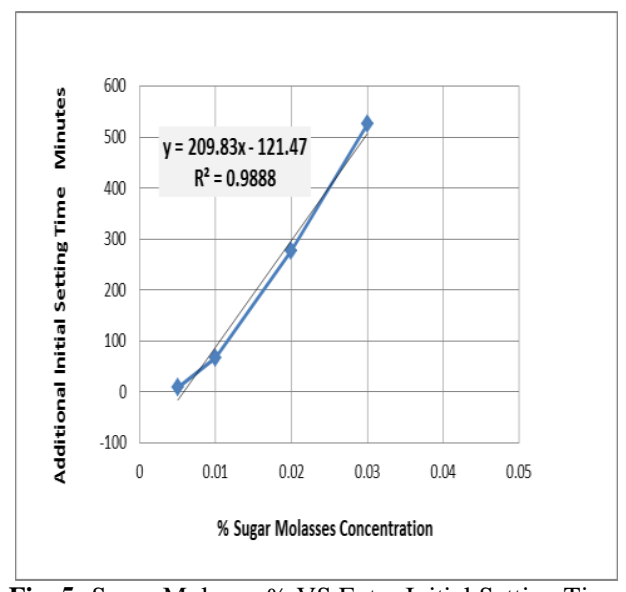

Fig. 5: Sugar Molasses\% VS Extra Initial Setting Time

\section{The Effect of Sugar Molasses onWorkability (Slump Concrete)}

The fresh concrete workability and its change with time were determined by using the slump test. The average slumps results obtained on all mixes at all interval periods are presented in "Tab. 5 ".

Table 5: Results of Slump Flow of Concrete

\begin{tabular}{|c|c|c|c|c|c|}
\hline \multirow{2}{*}{ SM \% } & \multicolumn{5}{|c|}{ Slump Flow, cm } \\
\cline { 2 - 6 } & 0 min. & 30 min. & $\mathbf{6 0}$ min. & 90 min. & $\mathbf{1 2 0}$ min \\
\hline 0 & 5.50 & 3.80 & 2.20 & 1.50 & 0.00 \\
\hline 0.05 & 6.65 & 6.20 & 4.80 & 3.20 & 1.40 \\
\hline 0.1 & 8.10 & 7.73 & 7.10 & 6.45 & 4.80 \\
\hline 0.2 & 17.5 & 12.3 & 9.8 & 7.6 & 6.60 \\
\hline 0.3 & 22 & 18.5 & 13.6 & 11.2 & 9.60 \\
\hline
\end{tabular}

Based on the experimental results, as the percentage (\%) of SM increased, the slump value also increased. The addition of SM to the concrete greatly influenced on the setting property and clear collapse of slump observed during the slump test at a dosage of $0.3 \%$ and the open of molds performed after two days. In all mixes, as the time increase, the slump loss value also increase linearly but by the lower percentage when the percentage of SM added increase, as shown in "Fig. 6".

However, the slump values remain within range between 1.4-6.6 $\mathrm{cm}$ for SM dosages of $0.05 \%$ and $0.2 \%$. Recession results indicate that molasses can be used as an effective mixture at hot weather concrete reached about $50^{\circ} \mathrm{C}$ temperature.

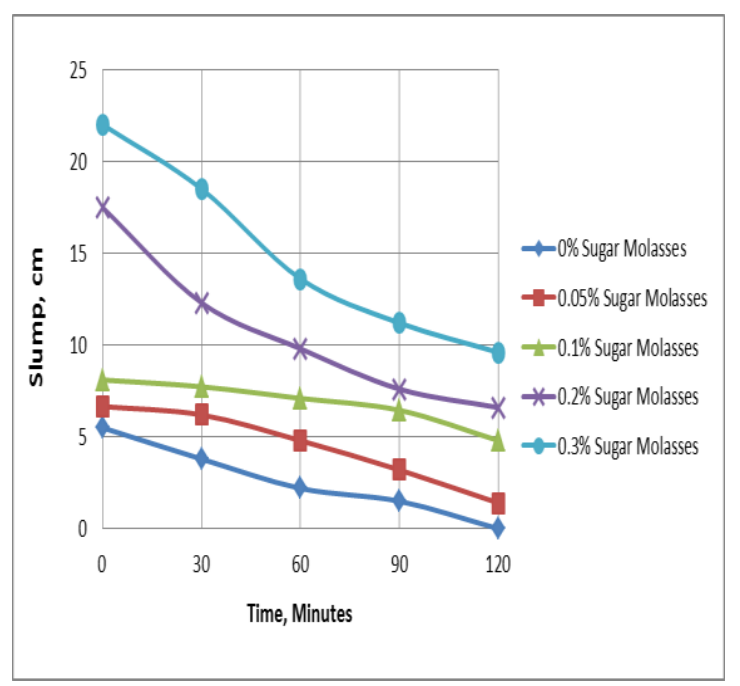

Fig. 6: Slump Value VS Time

\section{The Effect of Sugar Molasses of PH-Value in Concrete}

The $\mathrm{pH}$ of cement materials provides relevant information on the various chemical processes of cement materials. The $\mathrm{pH}$ is an important criterion in the study of concrete properties. Low and high $\mathrm{pH}$ creates a problem in concrete in terms of corrosion and spalling. The steel reinforcement bars used in concrete structures are prevented from corrosion by forming a thin layer of adherent passive oxide in a high $\mathrm{pH}$ environment of concrete. The high $\mathrm{pH}$ (usually 12.5 to 13.5 ) is performed by the formation of calcium hydroxide during cement hydration. This high basic level is good sufficient to keep the oxide film and protect it for a long enough time [28]. The $\mathrm{pH}$ results obtained for all mixes of concrete after 28 days are presented in "Fig. 7".

From the "Fig. 7" above, it was found that the results of $\mathrm{pH}$ values enable to use SM safely. It is found that the higher the molasses, the lower the $\mathrm{pH}$. 


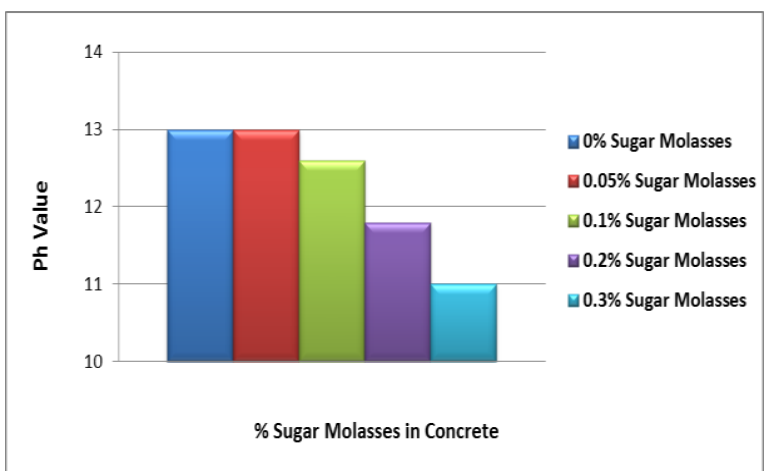

Fig. 7: pH Value For Concrete and Cement Paste

\section{The Effect of Sugar Molasses on Compressive Strength of Concrete}

The compressive strength results of the HSC with different dosages of SM at all ages are comparatively shown in "Fig. 8". As expected, the presence of SM in the concrete resulted in a reduction in early strength at a decreasing rate. The concrete mixes with SM dosages of $0.05 \%, 0.1 \%, 0.2 \%$ and $0.3 \%$ show a decrease in compressive strength by about 4.3\%, 6.3\%, 11.5 and 26.7\%; respectively at 7 days when compared with the control mixes (without SM). As is known and common, the reduction in compressive strength is mainly due to the tricalcium silicate rate, which is mainly responsible for the early strength development of cement. The addition of SM to the mixture delays the hydration of the tricalcium silicate due to its sugar content.

The compressive strength of the concrete at 14 and 28 days gradually increases with the use of SM up to $0.2 \%$ and decreases as the dosage value increases beyond this limit. This can be attributed to the retarding effect which works on the more denser and uniform internal structure. However, the compressive strength values obtained in 28 days of curing are within the acceptable range of HSC for all mixes except $0.3 \% \mathrm{SM}$ mix. The increase in compressive strength at 28 days was about $2.6 \%, 6.2 \%$ and $11.2 \%$ for mixes with SM dosages of $0.05 \%, 0.1 \%$ and $0.2 \%$; respectively; while, the decreasing was about $15.7 \%$ for $0.3 \%$ SM mix. This result shows that considering compressive strength values, SM can used natural up to $0.2 \%$ weight of the cement in concrete production in hot weather condition as a retarder admixture.

The development of compressive strength versus ages at different dosages of SM added to the mixes is shown in "Fig. 9"

Experimental results in "Fig. 9"show that, as the curing time of concrete expanded to about 10 days, the concrete prepared with SM gave better compressive strength than control mix at all percentages of dosage except $0.3 \%$ SM mixes. This improvement in strength was more pronounced at $0.2 \% \mathrm{SM}$ mix. These results can be explained by a mechanism proposed by Juenger and Jennings [9]. According to the their proposal, the addition of SM to the concrete mix increases the initial dissolution of ions and results the formation of a protective layer around the grains of cement to prevent contact with the water. The ions are activated in the pore solution independently rather than linked to the poisonous sites present during the period of retardation. When the effects of SM poisoning are overcome by increasing the ions in the solution, these ions interact with each other to increase the hydration products. These reactions improve the strength of the concrete after early ages of curing.
SM content of $0.2 \%$ of cement weight can improve compressive strength by about $11.2 \%$ at 28 days and delay initial setting time by about 4.617 hours (277 minutes). No adverse effect on concrete have been observed at this dosage of SM concentration for the ages of concrete cylinders studied. Delays in the setting of concrete at this dosage of SM content can be helpful in reducing the early setting of concrete and therefore may be prevented cold joints formation in concrete elements under Iraqi hot weather condition

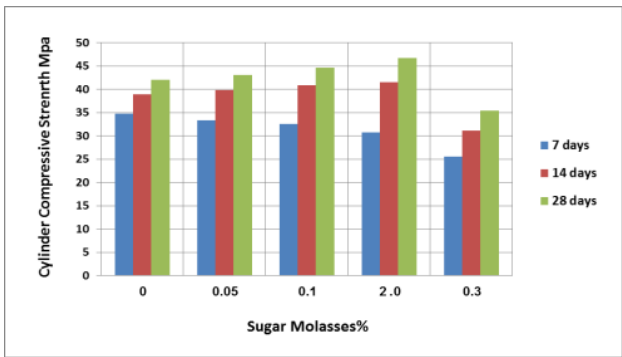

Fig. 8: Compressive Strength Versus Ages at Different SM\%

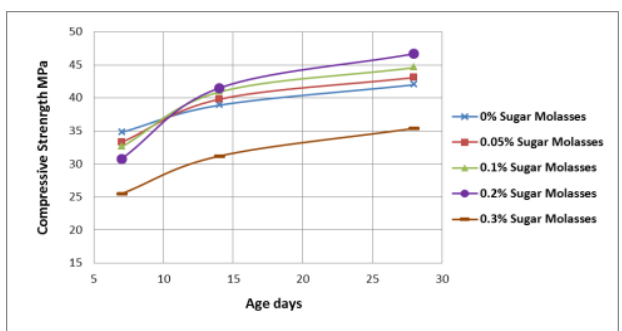

Fig. 9: Development of Compressive Strength Versus Ages for All Concrete Mixes

\section{Influence of Construction Joints on the Concrete Beams Behavior}

Based on the experimental results, "Tab. 6" shows the compressive strength $\left(f_{c^{\prime}}\right)$ and splitting tensile strength $\left(f_{s p}\right)$ for each layer/part of beam versus the failure load in beam.

\section{A. The Effect of Using Sugar Molasses on Construction Joint}

From the experimental results, it is observed that, the failure load of monolithic beam with SM increased by about $14.23 \%$ as average when compared with monolithic beam without SM. Whereas, in case of horizontal construction joints the failure load for concrete with SM compared with concrete without SM increases by about (19.65-25.60)\% and (16.57-24.23)\% in smooth and rough planes; respectively. The failure load for the beams with SM of smooth and rough vertical joints is in the range between (1.95 - 2.12) and (1.461.37); respectively times that of the case of beam without SM. "Fig. 9" shows the beams with/without SM in smooth planes.

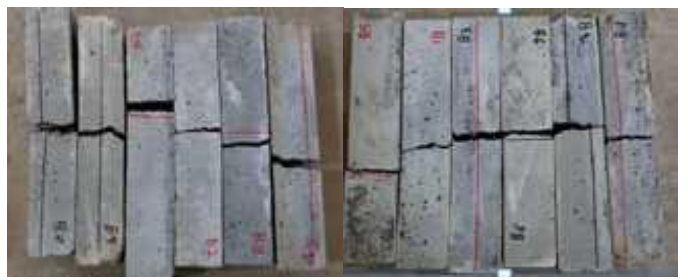

Fig. 10: Beams with/without SM in smooth plane

\begin{tabular}{|c|c|c|c|c|c|}
\hline \multirow[b]{2}{*}{ Beam symbol } & \multicolumn{3}{|c|}{ Mechanical properties of beam } & \multirow[b]{2}{*}{ Failure load $(\mathbf{k N})$} & \multirow[b]{2}{*}{$\%$ Decrease* } \\
\hline & Layer / part Description & $\begin{array}{c}f_{c^{\prime}} \\
M P a\end{array}$ & $\begin{array}{c}f_{s p} \\
M P a\end{array}$ & & \\
\hline B1 & control & 42.8 & 3.96 & 30.54 & - \\
\hline \multirow{2}{*}{ B2 } & 1 st layer & 42.1 & 4.14 & \multirow{2}{*}{28.20} & \multirow{2}{*}{-7.66} \\
\hline & 2nd layer & 42.6 & 3.76 & & \\
\hline \multirow{2}{*}{ B3 } & 1st layer & 41.8 & 3.93 & \multirow{2}{*}{27.48} & \multirow{2}{*}{-10.02} \\
\hline & 2nd layer & 41.7 & 3.28 & & \\
\hline
\end{tabular}




\begin{tabular}{|c|c|c|c|c|c|}
\hline \multirow{2}{*}{ B4 } & 1st layer & 42.3 & 3.98 & \multirow{2}{*}{25.40} & \multirow{2}{*}{-16.83} \\
\hline & 2nd layer & 41.6 & 3.76 & & \\
\hline \multirow{2}{*}{ B5 } & 1st part & 42.8 & 3.06 & \multirow{2}{*}{11.84} & \multirow{2}{*}{-61.23} \\
\hline & 2nd part & 43.0 & 2.64 & & \\
\hline B6 & 2nd part & 43.2 & 2.92 & 12.24 & -59.92 \\
\hline B7 & control & 45.6 & 2.78 & 35.22 & - \\
\hline B8 & 1st layer & 46.5 & 3.03 & 33.92 & -3.69 \\
\hline \multirow{2}{*}{ B9 } & 1st layer & 46.4 & 3.31 & \multirow{2}{*}{32.88} & \multirow{2}{*}{-6.64} \\
\hline & 2nd layer & 45.8 & 3.33 & & \\
\hline \multirow{2}{*}{ B10 } & 1st layer & 42.9 & 4.14 & \multirow{2}{*}{31.90} & \multirow{2}{*}{-9.43} \\
\hline & 2nd layer & 43.4 & 3.75 & & \\
\hline \multirow{2}{*}{ B11 } & 1st part & 44.3 & 3.91 & \multirow{2}{*}{23.06} & \multirow{2}{*}{-34.53} \\
\hline & 2nd part & 44.4 & 3.94 & & \\
\hline \multirow{2}{*}{ B12 } & 1st part & 45.0 & 3.94 & \multirow{2}{*}{25.91} & \multirow{2}{*}{-26.43} \\
\hline & 2nd part & 45.2 & 3.80 & & \\
\hline \multirow{2}{*}{ B14 } & 1st layer & 41.8 & 2.83 & \multirow{2}{*}{29.88} & \multirow{2}{*}{-3.61} \\
\hline & 2nd layer & 43.1 & 2.85 & & \\
\hline B15 & 1st layer & 42.0 & 2.90 & 2905 & -629 \\
\hline В15 & 2nd layer & 43.0 & 2.80 & 29.00 & -0.29 \\
\hline B16 & 1st layer & 41.6 & 3.31 & 2679 & \\
\hline В16 & 2nd layer & 41.5 & 3.61 & 20.19 & -13.58 \\
\hline & 1st part & 41.5 & 3.37 & 1742 & -4381 \\
\hline В17 & 2nd part & 41.0 & 3.35 & 17.42 & -43.81 \\
\hline B18 & 1st part & 41.6 & 4.22 & 1091 & -3577 \\
\hline D 18 & 2nd part & 42.4 & 3.66 & 19.91 & -35.11 \\
\hline B19 & control & 46.6 & 3.84 & 35.07 & - \\
\hline В 20 & 1st layer & 45.8 & 3.85 & 3483 & -068 \\
\hline B 20 & 2nd layer & 44.5 & 3.86 & 34.83 & -0.08 \\
\hline B21 & 1st layer & 44.3 & 3.65 & 3470 & -106 \\
\hline B21 & 2nd layer & 45.7 & 3.16 & $34 . / 0$ & -1.06 \\
\hline B22 & 1st layer & 46.1 & 2.55 & 3328 & -510 \\
\hline B23 & 2nd part & 44.0 & 2.82 & 25.43 & -21.49 \\
\hline B24 & 1st part & 46.1 & 3.85 & 2725 & (2) 32 \\
\hline B 24 & 2nd part & 46.6 & 3.87 & 21.25 & -22.50 \\
\hline
\end{tabular}

\subsection{The Effect of Plane Texture of Construction Joint}

The effect of plane texture of construction joints; its effect is evident in the case of concrete without SM and in vertical joints beams. The experimental results, observed that increasing the coefficient of friction by roughed plane of construction joints causes an increase in the failure load by about $47.13 \%$ and $62.62 \%$ in concrete beams without SM of vertical joints at 33\% and 50\% of length; respectively. This is attributed to reducing the slip amount at the joint and increase shear resistance. In concrete beam with $\mathrm{SM}$, the rough plane have slight effect on the behavior; the increase in failure load was about $10.28 \%$ and $5.17 \%$ in concrete beams with SM of vertical joints at $33 \%$ and $50 \%$ of length; respectively The effect of surface plane was very slight in cases of horizontal construction joints beam with/without SM because the horizontal joints have a slight effect on the decrease in load of failure, there is no apparent effect of roughness of the joint surface

\subsection{The Effect of Type and Location of Construction Joint}

It is clear that the failure load in general in horizontal construction joints, have slight effect and less than of the failure load by about $(0.68-16.83) \%$ as compared to the experimental results for monolithic beam. Whereas, in the case of the vertical construction joints; have a great effect, the experimental failure load is less than the monolithic beam by about (22.30 - 61.23)\%, with an average of $42 \%$ as shown in "Tab. 6". All beams were failed in flexure except beams of vertical cold joint at 33\% length were failed in shear. The horizontal construction joint in compression zone of beam have the more effect of decreasing in failure load by about $9.43 \%$ and $16.83 \%$ in concrete beam with and without SM; respectively and less than that in the case of rough surface. During the present work, it is found that the vertical construction joint is preferable to be located within the middle third of the beam span. For beams having a vertical construction joint, it is found that the location of the joints has almost same effect on the failure load capacity of the concrete beam without SM in smooth plane. In other cases of vertical construction joint, the location at $33 \%$ length the beam have the more effect of decreasing failure load by about $43.53 \%$, $43.81 \%$ and $27.49 \%$ for concrete with SM, concrete without SM with rough plane and concrete with SM with rough plane; respectively.

\section{Conclusion}

The optimum dosage of sugar molasses is $0.2 \%$ of cement weight which can improve compressive strength by about $11.2 \%$ at 28 days and delay initial setting time by about 4.617 hours (277 minutes). Which can be reduced the impact of the cold joints formation in concrete beams under Iraqi hot weather condition. The horizontal construction joints have slight effect while, the vertical type; have a great effect on the ultimate capacity of concrete beam. The vertical construction joint is preferable to be located within the middle third of the beam span and the horizontal type in tension zone of beam. The plane texture of construction joints have more effect in the case of concrete without SM.

\section{References}

[1] Critchell P., "Joints and Cracks in Concrete ", CR Books (A Maclaren Company), London, 1968. 
[2] G. R. Otoko, Minimising hot weather effects on fresh and hardened concrete by use of cassava powder as admixture, (2014) European International Journal of Science and Technology Vol. 3 No. 2 pp. $1-8$.

[3] Kleinlogel, Influence on Concrete, Frederick Ungar Publishing, New York, 1950, pp. 222- 223.

[4] H.F. Gonnerman, Job problems and practice. A concrete floor in a candy factory? Proc. Am. Concr. Inst. 35 (1938-39) 116

[5] M. C. G. Juengera and H. M. Jennings, New insights into the effects of sugar on the hydration and microstructure of cement pastes, Cement and Concrete Research 32 (2002) 393-399.

[6] R. Ashworth, Some investigations into the, use of sugar as an admixture to concrete, B.Eng., A.M.I.C.E, Paper No. 6770 (1965), for written discussion, pp.129-145.

[7] N. L. Thomas and J. D. Birchall, The retarding action of sugars on cement hydration, cement and concrete research (1983) Vol. 13 , No. 6, pp. 830-842.

[8] K. Luke and G. Luke, Effect of sucrose on retardation of Portland cement, Advances in Cement Research, (2000), Vol. 12, No. 1, pp.9-18.

[9] M. C. G. Juenger and H. M. Jennings, New insights into the effects of sugar on the hydration and microstructure of cement pastes, Cement and Concrete Research (2002) No.32 pp.393-399.

[10] E. Abalaka, Effects of Sugar on Physical Properties of Ordinary Portland Cement Paste and Concrete, ATBU Journal of Environmental Technology (AU J.T.) (2011) Vol.14,No.3pp. 225228.

[11] E. Abalaka, Comparative Effects of Cassava Starch and Simple Sugar in Cement Mortar and Concrete, ATBU Journal of Environmental Technology (AU J.T.) (2011) Vol.14,No.1pp. 13 22.

[12] F. Mazumder, Effect of sugar on setting time of Portland cement, proceedings of 3rd International Conference on Advances in Civil Engineering (2016), Chittagong, Bangladesh; pp. 349-352.

[13] H. M. Husain and D. M. Hamza, Analysis of corner beam-column junction with Inclusion of the effect of construction joints, Journal of Engineering (2007), Vol. 13 No.2.

[14] M. Metwally and M. S. Issa, Influence of horizontal construction joint on the flexural behaviour of reinforced concrete slabs, (2007) HBRC Journal VOL. 3 No. 3.

[15] Q. Abdul-Majeed, Evaluation of Transverse Construction Joints of Reinforced Concrete Beams, (2010) Eng. \& Tech. Journal, Vol.28, No.14.

[16] Q. Abdul-Majeed, L. A. Ghaleb and M. G. Ghaddar, Effect of the Number of Horizontal Construction Joints In Reinforced Concrete Beams, (2010) Eng. \& Tech. Journal, Vol.28, No.14.

[17] Z. W. Abass, Effect of Construction Joints on Performance of Reinforced Concrete Beams, (2012) Al-Khwarizmi Engineering Journal, Vol. 8, No. 1, PP 48- 64.

[18] Y. Ali and W. H. Mahdi, Behavior of Reinforced Hybrid Concrete Corbel-Column Connection with Vertical Construction Joint, (2017) Journal of Babylon University, Vol. 25, No. 1, PP 30- 44.

[19] Iraqi Specification Standards IQS No. 5, 1984 "Portland Cement", Central Agency for Standardization and Quality Control, Planning Council, Baghdad, IRAQ (in Arabic).

[20] Iraqi Specification Standards IQS No.45, 1984 "Aggregate from Natural Sources for Concrete and Construction", Central Agency for Standardization and Quality Control, Planning Council, Baghdad, IRAQ ( in Arabic).

[21] ACI 363R-92, 1998 (Reapproved 1997) " State-of-the-Art Report on HSC", ACI Manual of concrete practice, Part1, PP. 55.

[22] ASTM C 192/C 192M-05, "Standard Practice for Making and Curing Concrete Test Specimens in the Laboratory", Annual Book of ASTM Standards, American Society for Testing and Materials, pp.1-8, 2005.

[23] Mehta, P. K. and Monteiro P. J. M., " Concrete. Microstructure, properties, and materials " McGraw-Hill ,Third Edition (2006), 684 pp.

[24] ASTM C 143/C 143M-05a, "Standard Test method for Slump of Hydraulic-Cement Concrete", Book of ASTM Standards, American Society for

[25] ASTM C 39/C 39M-05, 2005 "Standard Test Method for Compressive Strength of Cylindrical Concrete Specimens" Annual Book of ASTM Standards, Vol. 04.02 Concrete and Aggregates, West Conshohocken, PA, United States, 7 pp

[26] ASTM C 496/C 496M-04, "Standard Test Method for Splitting Tensile Strength of Cylinder Concrete Specimens", Annual Book of ASTM Standards, American Society for Testing and Materials, 2004
[27] ASTM International (2008) F710-08 Standard Practice for Preparing Concrete Floors to Receive Resilient Flooring.

[28] V. Kumar, " Protection of Steel Reinforcement for Concrete: A Review ", (1998) R \& D Centre for Iron \& Steel, Vol. 16, No. 4 